Article

\title{
Sustainable City Lighting Impact and Evaluation Methodology of Lighting Quality from a User Perspective
}

\author{
Melita Rozman Cafuta
}

Citation: Rozman Cafuta, M. Sustainable City Lighting Impact and Evaluation Methodology of Lighting Quality from a User Perspective. Sustainability 2021, 13, 3409. https:// doi.org/10.3390/su13063409

Academic Editor: Gwanggil Jeon

Received: 3 March 2021

Accepted: 17 March 2021

Published: 19 March 2021

Publisher's Note: MDPI stays neutral with regard to jurisdictional claims in published maps and institutional affiliations.

Copyright: (C) 2021 by the author. Licensee MDPI, Basel, Switzerland. This article is an open access article distributed under the terms and conditions of the Creative Commons Attribution (CC BY) license (https:// creativecommons.org/licenses/by/ $4.0 /)$.
Faculty of Civil Engineering, Transportation Engineering and Architecture, University of Maribor, Smetanova ulica 17, 2000 Maribor, Slovenia; melita.rozman-cafuta@um.si

\begin{abstract}
High quality artificial lighting of public places is one of the necessary functions of sustainable cities. It is much more than just providing sufficient light intensity with reduced energy consumption and low environmental impact. The solution to this challenge is not only technological, but also requires the consideration of the subjective approach, such as psychological, sociological, and aesthetic-functional. The article presents the SEC (Suitable for everyone, Environmentally-accepted, Cost-effective) methodology and model, which are placed in the context of sustainable city lighting. A holistic assessment approach of user environmental perception, priorities, and spatial responses is required to evaluate the impact of artificial night illumination. Lighting efficiency was expressed as the correspondence between environmental perception and spatial utilization during day and night. Ten sites with different urban background and illumination characteristics were selected. It was assumed that artificial night lighting influences the perception, priorities, and responsiveness of users. The validity of this argument was demonstrated at a relevant statistical level of $p<0.05$. The research results provided useful information about the current state, which is needed to prepare a sustainable lighting strategy, and could be compared between different or similar sites. Based on the obtained results, it can be concluded that the artificial lighting of urban open spaces is of high quality when the difference in the spatial perception and spatial utilization between day and night is as small as possible.
\end{abstract}

Keywords: artificial night lighting; evaluation framework; lighting quality; urban open space; sustainability model SEC; environmental perception

\section{Introduction}

Light is an important environmental factor that can do much more than illuminate. As a source of energy, it influences all life on the planet. For humans, it is of immediate importance as a message carrier that enables visual stimuli. Visual perception provides us with two thirds of all environmental information [1]. The need to subordinate the environment to modern patterns of life is the reason for supplementing natural lighting. Artificial night light is important because it can enhance form and function, increase the safety of people, property, and traffic, and create flexible spaces that adapt to the task at hand [2]. It means satisfying socio-psychological needs and thus improving living and working conditions. It enables a continuous development of urban space so that it corresponds to the forms of life for which it is intended. It also contributes to the creation of a spatial identity, as light enables the visual highlighting of each spatial component.

Illuminated areas are an important integral part of cities and other urban areas. Already, Lynch [3] defended the idea that the fundamental urban structure should be respected as an important tradition; construction lines and street corridors must be protected; the planned directions and ideas must be developed or continued. Only in this way is a long-term development of the city possible. Especially because a concept of urban landscape is not only a material reality, but a mental structure resulting from subjective perception. We experience urban structures as part of the visual environment. City lighting can influence the visual quality of the environment, enables a better recognition of 
structural relationships, influences the mental image of the urban space, and thus further strengthens the identity of the city. According to Huber [4], high quality illuminated surfaces are more attractive and are therefore used more often. Optimizing lighting in the direction of improving the quality is already necessary to reduce costs.

The lighting is not always suitable for all users. The environment can give us more messages than we can accept. We select only those messages that are important and useful to us at a particular time, and only as much as we can process [5]. Both lack of light and excess light influences the quality and quantity of these messages. This inconsistency can cause discomfort, inappropriate behavior, or wrong reactions in a certain situation. The consequences manifest themselves in a deterioration in the quality of living space and in behavioral changes, i.e., the sleep pattern was shortened from nine to seven hours per night [6].

An urban place is a socio-physical construct consisting of buildings, streets, spaces, different land uses, and a community of users [7]. If the places are unattractive for the users or they do not feel safe there, this may be due to a poor arrangement of the place, which basically does not offer enough interesting possibilities. One possible reason may be poor outdoor lighting, especially if this condition occurs at certain time intervals. The presence or absence of night light as a quality of the physical environment has the greatest impact on large green spaces such as parks and all other paved areas such as public squares or streets. Such a situation leads to conflicts between different user groups and undoubtedly results in a low number of visitors on such areas.

While humans primarily benefit from light, the presence of artificial night light in urban environments impacts ecosystems, animals, and vegetation. The emission of light is rarely neutral and can have serious ecological and evolutionary consequences for many organisms and may reshape entire ecosystems [8]. Light reflected from illuminated surfaces also causes skyglow and alters natural conditions. Some insects or birds are attracted to artificial light [9]. Their behavioral patterns, migration routes, and reproductive schedules are affected. Longcore and Rich [10] found that artificial night light changes the relationship between predators and prayers. Predators might be more successful at hunting, but prays adapted to darkness might be confused by too much additional light. It is not only the direct light that seems to be problematic. The presence of the city increases the intensity of the light in a wider radius. It manifests itself in the form of skyglow that can be perceived from a great distance. Longcore and Rich [10] (2004) conclude that this phenomenon can also change the behavioral patterns of animals that are not directly associated with urban space. Skyglow is not exclusive to cities as such, but indeed is usually stronger in urban areas.

Oversized illuminance level has a completely different effect on plants. For green organisms, the following parameters are important: The value of the light spectrum, the light intensity, the light direction, and the duration of light exposure. Briggs [11] states that night light accelerates the growth cycle of plants, resulting in faster seed germination, thicker leaf, faster stem growth, faster transition to flowering stage, and faster fruit ripening. Although these effects may even seem desirable, they often lead to abnormalities in the vegetative parts of the plants.

Widely discussed are the negative effects of the introduction of artificial night lighting on human health. Evidence suggests that these effects may be significant due to the impact of nighttime exposure to artificial light on the suppression of melatonin. Inappropriate exposure to light at night may be associated with an increased risk of breast cancer and gastrointestinal and cardiovascular diseases [12]. Modern city concepts, such as smart and sustainable cities, nowadays all claim to be human-centered and inclusive [13]. By improving the understanding of citizens, their needs, perceptions, and behaviors, it is possible to promote government measures towards inclusive urban design [14].

Illumination is not always useful, especially when a dangerous glare is present. Glare provides visual irritation. Problems occur when conditions are so extreme that the human visual system cannot adapt. Too little or too much light is perceived as uncomfortable. 
In the worst cases, the response to a particular situation may be incorrect. Useless light, known as light pollution, is a particular form of environmental pollution caused by glare, light trespass in non-target areas, and skyglow [15]. Light pollution is not only a nuisance, but an ecological hazard. Environmental remediation begins once the source is eliminated. However, nocturnal light cannot be abolished simply to preserve nature.

Choosing the right type of luminaire is just as important as how much light is actually emitted into the environment. The technical properties make the luminaires interesting for users. Lighting elements that are not shielded are not suitable. The best choice is completely shielded luminaires. These shine evenly and have minimal glare. Appropriately lit streets are more attractive and frequently used. The appearance of the luminaires is important as an esthetic design element in the urban structures. In practice, the qualitatively illuminated areas are more attractive and are therefore frequently used [4]. Optimization of lighting towards quality improvement is imperative as it reduces operating costs. The parameters of urban space are constantly changing. High quality lighting ambiences have the ability to adapt to all spatial conditions. In practice, circumstances change due to different traffic densities and fewer users in the early morning or late evening hours. To ensure good living conditions for all, it is necessary to adapt the lighting ambiences. Oversized lighting alone is not enough; the lighting must also be functional.

Artificial light at night today should be a composition of environmental responsibility, economic efficiency, and social cohesion like suitability for the user. It should take into account the interests of the individual and society as a whole. Sustainability is based on the evaluation of the possibility of achieving such a quality and quantity of light sources that the level of lighting is consistent with the principles of sustainable development in terms of preserving human health [12], preserving ecosystems [10], reducing energy consumption, and contributing to human well-being [16], sociality, and economic vitality [12]. According to Balocco and Volante [16], sustainable lighting is an integrated set of lighting quality and energy efficiency solutions, which in detail means the use of efficient light sources integrated with an advanced control system.

Sustainable lighting is highly subject to technological advances in design with energy efficient light sources. There are many studies dealing with street lighting [17,18], advertising lighting [19], security lighting [20], and architectural lighting [21]. Outdoor lighting control is not a new concept. Intelligent dynamic street lighting that continuously adapts to user presence and behavior can illuminate the street only when and where it is needed. As such, it offers a solution to the energy waste and light pollution associated with conventional street lighting $[18,22]$. Recognizing and taking advantage of these opportunities is necessary to limit the use of light at night. In addition to technical innovations, institutions such as the Commission Internationale de l'Eclairage (CIE) [23], the Illuminating Engineering Society of North America (IESNA) [24], and the International Dark-Sky Association (IDA) [25] have proposed setting lighting limits based on the function of a given area. Areas that require light pollution control are divided into different light management zones depending on the amount of light required, so that outdoor lighting is not restricted equally in all areas [19]. For street lighting, it is quite easy to control the electrical power used, the efficiency of the luminaires and the upward artificial light to obtain a satisfactorily illuminated area with low environmental impact [17]. Streets, sidewalks, and bicycle paths are limited areas with intended activities (to move forward) and quantitative recommendation for street lighting. The Commission Internationale de l'Eclairage (CIE) describes three main purposes of street lighting: (1) To enable all road users to move forward safely; (2) to enable pedestrians to see hazards, orient themselves, recognize other pedestrians, and give them a sense of security; and (3) to improve the appearance of the environment during the day and night [26]. Street lighting guidelines and standards are intended to help designers achieve these goals. To do so, they provide quantitative recommendations for the appropriate level (luminance or illuminance), color (or other characteristics derived from spectral power distribution (SPD)), and spatial distribution of light [26]. Recommendations 
in form of energy indicators, environmental criteria, and photometric measurements are given for street lighting arrangements [17].

Outdoor lighting is an extremely broad topic. Under the technologically oriented aspect of energy efficiency, illuminance is a measurable entity. However, sustainable management also includes the human dimension. There can be no talk of an absolutely measurable lighting efficiency here-the perception of the environment is perceived differently by different people and depends on the spatial context (urban and architectural). The results of Laze's study [27] show that users were dissatisfied with the street lighting, although all light measurements were above the standards of CIE. The results indicate the need to improve street lighting to meet public expectations.

To limit the scope, this paper focuses on the public's cognitive and emotional perceptions of the nighttime environment and how the resulting public attitudes facilitate seemingly rational decisions for nighttime lighting. According to Doulos [17]., accurate lighting design is more important than selecting a less appropriate luminaire for urban sustainability based on price alone Our subjective perception depends on gender, age, time, experience, culture [28], and spatial context. Our priorities are psychological, sociological, and aesthetic. It is crucial to plan the light source distribution that takes into account the spatial conditions. The same type of luminaire can cause a different effect. It depends on where it is placed.

In the urban context, it is not only linear structures such as streets that are illuminated. There are also other public places such as public squares and parks, which are gathering points for people where they move all over the open surface. The most common activities there are walking, running, standing, sitting, socializing, playing, in-line skating, rollerblading, and sightseeing. Although many of these activities are primarily done during the day, it is possible to extend them into the night. Such places of architectural and advertising illumination tend to be unevenly lit. The absence or reduction of night lighting does not necessarily mean a low-quality environment, in fact it may be desirable (ability to see the night sky).

Focusing on a user-oriented approach to the physical environmental experience, the following questions are addressed:

(1) How do users perceive the nocturnal city?

(2) How does this spatial perception affect the use of open spaces?

(3) How can lighting quality be achieved from the users' point of view?

There is a tendency to answer all these questions, and the most important findings in this context are the following: Quality urban lighting means much more than providing an adequate amount of light and minimizing energy consumption. It cannot be achieved as a permanent state, but only as a set of desirable characteristics of a complex system composed of user satisfaction, environmental acceptance, and economic efficiency. In the context of the presented research, the starting point is the realization that a high-quality lighting ambience is primarily based on the needs of users in order to ensure their visual well-being, perceptual quality, and the fulfillment of the required visual tasks. Everything else is subordinate to this fact.

The null hypothesis here is:

Hypothesis $\mathbf{0}$ (H0). The users' perception of the environment and use of space during the day and at night are the same.

Consequently, the next two alternative hypotheses are set:

Hypothesis 1 (H1). The users' perception of the environment and use of space is different during the day and at night.

Hypothesis 2 (H2). By holistically assessing subjective indicators of lighting efficiency, it is possible to evaluate the impact of artificial night lighting in different urban open spaces. 
The comparison of the evaluation results between day and night environment cognition gives us information about the lighting efficiency. Of course, at this point the question remains to what extent this difference is influenced by artificial night lighting. The answers were sought through a detailed analysis of ten selected sites with different urban typology.

According to Fotios and Gibbons [26], technological changes have moved toward higher efficiency lamps, and light levels may have increased because the opportunity existed, not because any benefit from higher light levels was demonstrable. However, too much light or inappropriate light quality can also lead to wasteful energy consumption [29] and undesirable effects on the natural environment [26]. A multi-criteria evaluation procedure of lighting efficiency towards the inclusion of subjective indicators can be used as a tool to identify the most beneficial spatial solution. The research project presented here provides a methodological approach that could be a useful tool for the development of a sustainable lighting design considering preventive conservation. The case studies were used as a pilot and test project to check the extensibility, adaptability, and real-world applicability of the proposed evaluation methodology to all similar cases.

\section{Evaluation Assessment of Artificial Night Light Quality from a User Perspective}

The basic concept of quality is not new, but it acquires a useful meaning in today's world. Theoretically, five main approaches to definitions of quality are identified: The transcendental approach of philosophy, the product-based approach of economics, the userbased approach of economics, the production-based approach of operations management, and value-based approaches of business management [30]. From the user's perspective, quality is understood as the "superiority of something" or "fitness for use" [31]. "It consists of the capacity to satisfy wants" [32]. An object of quality has the ability to function satisfactorily in service and is suitable for its intended purpose. All user-based definitions start from the premise that quality lies in the eyes of the observer. This means that quality derives from personal needs and product perception. Durability is seen as an important element. According to Garvin [30], long-lived products are generally preferred.

Although the term quality was originally associated with the product, we use it today in other areas; as open space quality [33], environmental quality [7], residential quality [28], or in our case, as artificial night illumination quality. The definition that seems to be most generally applicable is that "Lighting quality is given by the extent to which the installation meets the objectives and constraints set by the client and the designer" [2]. Lighting quality is related to objectives such as improving the performance of relevant tasks, creating specific impressions, generating desired behavioral patterns, and ensuring visual comfort [34,35]. Kralikova et al. [2] distinguish between visual and psychological aspects. The first relates to visual comfort and the performance required for our activities, the second to the pleasantness of the visual environment and the adaptation of the environment to the activity. Other researchers define lighting quality as achieving an optimal balance between human needs, architectural considerations, and energy efficiency [36-38]. Johansson et al. [39] emphasized that "the subjective assessment of brightness" and "the perceived level of comfort in a lit environment" are the important elements that determine lighting quality. Subjective spatial-cognitive experience influences people's moods more than objectively measured lighting. In summary, lighting quality is much more than the provision of an adequate amount of light. It cannot be expressed only by photometric measures, nor can it be a single, universally applicable recipe for good quality lighting [40].

When talking about artificial night lighting in open spaces, durability is a synonym for sustainability. Quality principles are integrated. Sustainability is widely accepted as an important conceptual framework within which urban policy and urban development can position themselves [41]. As most human activities take place in cities and towns, investigating sustainability of urban areas is a critical task. On sustainability, it is crucial to know that "it is a fuzzy concept such that an activity can be partially sustainable, and an ideal fully sustainable society is unattainable" [42]. This concept alludes to all attempts made to improve the technical, social, environmental, and economic aspects of 
development in the biosphere and to protect natural resources [43]. Sustainability derives primarily from ecology as a capacity to endure. It is the way in which biological systems remain diverse and productive indefinitely. It is based on the "three pillars of sustainability, in which both economy and society are constrained by ecological limits" [44] (pp. 36-37). Quality, on the other hand, results from the satisfaction of the users with the product or service. "The family of standards ISO 9000 for quality management systems is intended to help organizations ensure that they meet the needs of customers and other stakeholders while meeting the legal and regulatory requirements for a product" [45]. "In this context, user satisfaction in open spaces could also be included. In today's world we are very conscious of environmental protection. If the product or service does not lead to negative consequences for the environment, it is an ecological quality aspect. ISO 14000 is a family of standards related to environmental management, designed to help organizations minimize the negative environmental impact of their activities" [46].

It can be summed up as follows: Environmental care and the desire for well-being are an intersection between sustainability and quality. Sustainability principles deal with space under three aspects: Environment, economy, and society. On the contrary, the quality principles emphasized one aspect: The satisfaction of society, which is perceptible and whose subjective attribute can be understood differently by different people [46]. Artificial night lighting could be treated as a product that should satisfy the users within the spatial aspect of the urban environment. In this context, quality principles need to be incorporated into the societal aspect, which must also reflect concern for the wellbeing of users. Sustainability principles are superior. Since artificial lighting is subject to technological progress to a large extent, it is important that it also complies with the principles of sustainability and quality.

Some preliminary empirical research on comparative analysis of environmental perception evaluation between different time sequences has been conducted by Rozman Cafuta [46]. The author presents Three-Dimensional Evaluation SEC (Suitable for everyone, Environmentally-accepted, Cost-effective) model to assess the characteristics of urban space. The three basic dimensions of the model are derived from the sustainability principles. Dimension "suitability to everyone" is an upgrade from social cohesion; "environmental acceptance", from environmental responsibility; and cost-effectiveness, from economic efficiency. SEC model belongs to a group of multi-criteria evaluation models that support the planning, design, and decision-making process. The model SEC provides a theoretical tool for evaluating the visual quality and visual potential of a particular place. Its application provides uniform units of measurement. How can we find out what is perceived as positive or negative around us? The model was designed primarily as a tool for multiple applications to compare results before and after spatial interventions or spatial development tracking over time. A single model application at a specific location provided results such as the assessment of visual arrangements at the specific location, the assessment of unused potential, and the recognition of specific spatial circumstances. The last option was used in the presented research.

Ideas are gradually evolving in science. The preliminary version of the evaluation model of artificial night light in urban environments [47] was not satisfactory. Moreover, the model has not been tested in practice, nor has an appropriate assessment methodology been developed. For the moment, the use of SEC methodology [46] seems to be a suitable tool, but the planned research required extensibility, adaptability, and real-world applicability of the methodology. The evaluation of the influence of artificial night light in different urban open spaces requires updating the factors and indicators. Moreover, the SEC methodology has not yet been satisfactorily tested in practice (it has been tested only in two squares with similar urban background). In order to demonstrate the flexibility of the SEC model and its applicability for a completely new purpose (lighting quality assessment), the basic structure of the three dimensions and related factors such as: Psychological, sociological, aesthetic-functional, ecological, technologic-functional, and economic, was adopted. The indicators have been upgraded to fit the new purpose (Table 1). In the course of the 
presented research, the methodology was tested in environments with different urban backgrounds.

Table 1. Three-dimensional evaluation assessment (model SEC (Suitable for everyone, Environmentally-accepted, Costeffective)) of artificial night light quality.

\begin{tabular}{|c|c|c|c|c|c|}
\hline Model Sec & & Dimensions & Factors & Indicators & \\
\hline \multirow{3}{*}{ 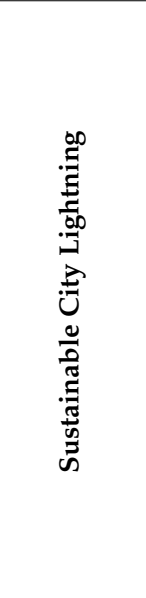 } & 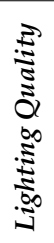 & 1. Suitability to Everyone & $\begin{array}{c}\text { 1.1 Psychological } \\
1.2 \text { Sociological } \\
1.3 \text { Aesthetic-functional }\end{array}$ & $\begin{array}{l}\text { 1.1.1 Individual feeling } \\
\text { 1.1.2 Attracting attention } \\
\text { 1.1.3 Orientation ability } \\
\text { 1.1.4 Sense of safety } \\
\text { 1.2.1 Land use } \\
\text { 1.3.1 Site aesthetic } \\
\text { 1.3.2 Light effect }\end{array}$ & subjective indicators \\
\hline & & $\begin{array}{l}\text { 2. Environmental } \\
\text { Acceptance }\end{array}$ & 2.1 Ecological & $\begin{array}{l}\text { 2.1.1 Impact on habitats } \\
\text { 2.1.2 Impact on living creatures }\end{array}$ & objective indicators \\
\hline & & 3. Cost Effectiveness & 3.1 Technologic-functional & $\begin{array}{l}\text { 3.1.1 Illuminance } \\
\text { 3.1.2 Light reflection from the surface } \\
\text { 3.1.3 Location of lights } \\
\text { 3.1.4 Appearance of lights } \\
\text { 3.2.1 Electricity cost } \\
\text { 3.2.2 Light efficacy } \\
\text { 3.2.3 Installation cost of infrastructure } \\
\text { 3.2.4 Maintenance cost of infrastructure }\end{array}$ & \\
\hline
\end{tabular}

When high-quality artificial lighting ambiences are created, they should first and foremost meet human needs. However, environmental perception is not universal, it is subjective. How should we evaluate spatial experience? The challenge is to introduce numeric into something that is basically not numeric. Modelling is useful to solve such a challenge by systematically assessing the environmental situation. Since we are focusing on users, the purpose of the research did not require the entire model implementation. To limit the scope, only the dimension suitability to everyone, which includes the artificial lighting quality aspect, is used. By identifying differences in spatial perception and use, lighting efficiency and indirectly lighting quality is evaluated.

\subsection{Psychologiscal Factor of Lighting Efficiency}

The image of the city results from the interweaving of building composition and open space. The recognizable and unique image of the city is already evident at the planning level. It is reflected in the structure of the system and is derived from the natural properties of the space. In a narrower sense, the image of the city is viewed from the perception (orientation) and experience of space (i.e., the identity of space). Identity is the basis for the development of a sense of belonging, and orientation is a function that enables individual mobility. Both are existentially necessary. They are also influenced by gender, age, education, status, mobility, lifestyle, and the social role of the individual.

When planning cities, there are some typical areas or points that need to be highlighted. These are: Entrance areas, main traffic corridors and footpaths, access to train and bus stations, urban green spaces and green corridors, embankments of watercourses, typical urban silhouette, panoramic views inside and outside the urban areas, and new urban compositions that must establish a relationship with the existing matrix, although they are themselves very recognizable and specific $[3,48]$. These visual qualities can be emphasized even more strongly with artificial night light. The most frequently illuminated components are traffic areas (roads, railways, airports), public areas (squares, parks), production facilities, commercial buildings and institutions, sports fields, cultural monuments, as well as construction sites and advertising facilities [49].

The spatial identity of the city changes at night. Reduced visibility creates a new relationship between open space and objects. Sometimes otherwise outstanding elements blur, gain different characteristics, or become equated with other elements of the urban complex. This way, artificial night lighting takes on the function of creating a night image 
of the city. Lynch [3] (p. 47-83) understands the urban structure as a basis that helps us to perceive the environment in order to gain spatial orientation. Artificial night lighting emphasizes the elements and creates completely new spatial arrangements. Light and darkness compose the strongest contrast, which changes the relationships between objects and open space. It is expected that signs, edges, and nodes will be illuminated with greater intensity and variety of colors. The lighting mode also creates a new hierarchy between paths and corresponding areas.

In summary, high-quality illuminated environments have greater visual potential; they can be more attractive and are therefore frequently used. Luminaires are important esthetic elements within urban structures [4]. However, not only the visual impact is important; the feeling of safety is much more important. Urban safety in the forms of individual safety $[18,20]$ and property safety $[50]$ is an issue that no city can ignore. There are various approaches to strengthening urban safety [51]. The safety index is one of the most commonly used indices for analyzing sustainable urban development together with models for assessing quality of life (Monocle's quality of life survey, Quality of life index (QLI)) [52]. However, new questions arise about the effect of lighting on perceived safety. We need to consider not only how much light pedestrians need to feel safe, but also which parts of the street should be lit. "Lighting indirectly influences safety perception through its effect on those environmental characteristics that are important for the safety appraisal process" [20]. Haans' and de Kort's experiment [18] with stationary and with walking participants resulted that people preferred to have light in their immediate environment rather than on the road ahead. This could be partly explained by changes in prospect (having an overview), escape (perceived escape possibilities), and concealment (perceived opportunities for offenders to hide). Contrary to expectations, prospect was higher in lighting distributions where the participants' immediate surroundings, but not the more distant parts of the street, were the most lit. In another study, van Rijswijk and Haans [20] propose that the positive correlation between perceived lighting quality and perceived environmental safety can be explained by co-occurring variation in appraisals of prospect, concealment, and entrapment. The results of their mediation analysis show that perceived quality of lighting is positively related to prospect, and negatively related to concealment and entrapment. Similarly, Pena Garcia et al.'s [53] research results show that well-lit streets (i.e., with uniform illumination) with higher illuminance levels make people feel safer and better. This pronounced preference for more light is less detrimental today because modern LED lighting allows higher illuminance levels with low power consumption. "Besides the lower economic and environmental impact of High-Pressure Sodium (HPS) lighting, stemming from the significant reduction in light pollution, the results generally indicated a better performance of this kind of lighting" [53]. Despite the fact that white light could lead to higher light pollution, it seemed to give people a sense of security. In conclusion, only appropriate light intensity and distribution can help to make the city a distinctive and pleasant place to live.

\subsection{Sociological Factor of Lighting Efficiency}

Urban public spaces give a sense of visibility to buildings and public life, as a precondition for the development of open space, and are highly related to urban sustainable development $[54,55]$. Environmental vitality is a key issue in studying urban open space [56] and providing a sustainable human-based public environment [57]. Urban open spaces are not only defined by giving meaning to the visibility of building blocks. Public life is a prerequisite for the development of open spaces [58]. "Just as it is possible to create a certain palette in a city by the choice of materials and colors, so it is also possible to influence patterns of activities through planning decisions, to create better or worse conditions for outdoor events and to create lively or lifeless cities," reported Gehl [59] (p. 33). People take on different roles such as living, working, leisure, etc. Their attitude to space varies according to the role they are currently playing. Consequently, not only the 
formal network of public spaces is important, but also a network of contacts, connections, and activities.

The modern lifestyle creates new user needs. In practice, this often means increasing the intensity of lighting in places that are frequently used. However, the current situation is often unsatisfactory. Some unused sites have great potential for improvement due to their location and content. These sites are often not self-contained and self-sufficient. They are limited to certain objects or the wider surroundings. Content specificity, size of the site, presence of people, functionality, and pleasant ambience are most often identified as potential. Such locations with often unused lighting possibilities are: Squares and open spaces in front of buildings, empty spaces and parking lots next to shopping centers, open spaces of industrial zones, outdoor areas of primary schools and kindergartens, and outdoor areas of nursing homes and city parks [47]. However, spatial challenges cannot be solved solely by creating specific lighting ambiences at the micro location itself. Planning for the efficiency of artificial night lighting must be addressed at the urban planning level.

Urban spaces are democratic when they are accessible to all groups and allow freedom of action, temporary appropriation, and control. They are responsive if they meet the needs of the various users and are meaningful if they offer comfort, relaxation, activity, and exploration [60]. Artificial night light strongly influences the components like responsiveness and sense of meaning. The quality and intensity of the lighting can influence the feeling of comfort, satisfaction, and relaxation in a positive or negative direction. Gehl [59] (pp. 11-14) presented a probabilistic approach to understand how design influences behavior. He argued that through design it is possible to influence how many people use open spaces, how long individual activities last, and what types of activity can develop. The activities are divided into three categories: "Necessary activities" (obligatory, users have no choice), "Optional activities" (voluntary activities, at the request of users), "Social activities" (spontaneous, when spatial conditions are favorable). Users perceive their physical environment as a set of properties that make something possible. Successfully designed public spaces such as plazas or parks facilitate positive social interactions and are well frequented. The architectural design and urban purpose of the space influence how the space is used. The presence or absence of night lighting as a physical feature or low lighting efficiency can affect all those areas that are primarily used for optional and social activities. Night-time environmental design can lead to conflicts between different user groups, which in turn leads to even lower visitor numbers. Carmona et al. [61] believe that the crux of Gehl's argument is that only the absolutely necessary activities take place in public spaces of poor quality. In higher quality public spaces, necessary activities take place at about the same frequency-although people choose to make them longer, but more importantly, there is also a wide range of optional (social) activities. Satisfactorily lit environments can contribute to the expansion of the activities carried out and the large number of users. Such places can maintain their optional and social role.

\subsection{Aesthetic-Functional Factor of Lighting Efficiency}

Today it is accepted in various disciplines that artificial night light is a quality that allows normal activities at a time when daylight is not available and additional lighting is urgently needed. The intensity of light has a significant impact on the ability to perceive. According to Dabbagh [62], color and light intensity play an important role in the beautification and readability of the city. If the lighting does not support the spatial requirements, the environment is frustrating. What kind of light do people appreciate and what repels them? An illuminated object that stands out from the dark surroundings is perceived as the most visually effective. Reducing the contrast between the illuminated object and the dark environment increases the difficulty of recognizing the spatial order.

Debreczeni [63] presents the following factors of lighting quality: Luminance, uniformity of illumination, glare, light color, direction of light, and constancy of illumination over time. Pellegrino [64] also looks for solutions in the direction of technological and aesthetic improvements. He believes that lighting technology brings lighting closer to the various 
users. According to Santen [65], the lighting quality is assessed on the basis of the overall brightness at the chosen location, the distribution of light according to purpose, and the perceived well-being of the users at the chosen location. All of this depends not only on the choice of a suitable lamp, but also on the material and texture of the surfaces and the color of the light.

Dark surfaces absorb much more than light surfaces; smooth surfaces reflect more than structured ones. Straight, flat surfaces do not cast shadows, whereas highly structured surfaces do. The interplay of light and shadow creates visually attractive components and is desirable, but too much contrast is considered unsuitable [65]. Santen [65] believes that the aesthetic aspect of the environment is a result of the relationship between light intensity, light color, and surface texture. Narboni [66] observes that humans initially and most easily perceive punctual lighting and later light strips of varying intensity, from the brightest to the darkest. According to Veitch [38], vertical, constantly illuminated smooth surfaces are most acceptable. Color contrasts are accepted as interesting as punctual lighting. Colored elements create visual guidance and are considered more striking.

In summary, the common characteristics of successful public spaces are identifying and responding to the needs of users, promoting different activities, and providing access to all user groups. Both in open green spaces (squares, parks) and on the streets, it is highly desirable that the use of the space is diverse, i.e., that it allows both primary and secondary use. It is important to have a safe, adapted, and clear environment. Boundaries must be clearly visible, as well as the points where it is "safe" to stop. High quality exterior design and artificial lighting are factors that have a significant impact on the subjective indicators. There seems to be general agreement that basic visual comfort requirements relate to illuminance levels in the visual field $[37,67,68]$. The last applies to both outdoor and indoor environments.

\section{Evaluation Methodology}

After analytical research on various spatial case studies and existing literature, a key question was set: How to assess the correspondence between the users' perception of the environment and the use of space in a given location in order to obtain comparable numeric knowledge of lighting efficiency in order to gain lighting quality. The SEC methodology was developed to evaluate visual arrangements at arbitrary locations [46]. A new category called "aspects" was added (Table 2). The first version of the methodology was tested in two squares with a similar urban background. The similar principle was used in the present study, but some aspects and the corresponding terms of the questionnaire were changed to better fit (Table 2). The aspect "dominance" was omitted; the aspects "interesting" and "pleasant" were substituted. Initial research [46] showed that these three indicators were confusing in context. The responders had difficulty understanding the scope.

An assessment tool (Questinaire) was used to support the assessment methodology. Each indicator was divided according to the relevant aspects and supported by questionnaire terms. Similar to the study conducted by Rozman Cafuta [46], the questionnaire consisted of four parts.

First, the respondents rated the specific site in terms of their personal attitude on a fivelevel evaluation scale between two extremes, such as: Not attractive-attractive, unpleasantpleasant, tense-relaxed, simple-complex, boring-interesting, not arousing-arousing, not visible-visible, and the last dangerous-safe. In the second part, the respondents were encouraged to estimate their frequency of visits to a certain place from "do not visit" to "always visit". Thirdly, the respondents evaluated the site aesthetics between disordered and ordered options. The last part dealt with the artificial lighting effect evaluated at night. The respondents assessed the degree of fascination, comfort, and compliance. The questionnaire covered all aspects listed in Table 2. Using the questionnaire, we obtain comparable numerical results that allow us to identify specific spatial conditions in a given location. The results could also be compared as evaluations conducted at the same location 
but at different time sequences (e.g., day and night). Sites with similar or different urban backgrounds could also be compared. The presented research covered all possibilities.

Table 2. Aspects and corresponding questionnaire term possibilities within two extremes (adopted from [11]).

\begin{tabular}{|c|c|c|c|}
\hline Factors & Indicators & Aspects & $\begin{array}{l}\text { Questionnaire Term Possibilities } \\
\text { within Two Extremes }\end{array}$ \\
\hline \multirow{5}{*}{ 1.1 Psychological } & 1.1.1 Individual feeling & $\begin{array}{ll}\text { - } & \text { Attraction } \\
\text { - } & \text { Pleasantness } \\
\text { - } & \text { Relaxation }\end{array}$ & $\begin{array}{l}\text { not attractive-attractive } \\
\text { unpleasant-pleasant } \\
\text { tense-relaxed }\end{array}$ \\
\hline & \multirow[t]{2}{*}{ 1.1.2 Attracting attention } & $\begin{array}{ll}\text { - } & \text { Composition } \\
\text { - } & \text { Arouse interest }\end{array}$ & $\begin{array}{l}\text { simple-complex } \\
\text { boring-interesting }\end{array}$ \\
\hline & & - $\quad$ Stimulation & not arousing-arousing \\
\hline & \multirow{2}{*}{$\begin{array}{l}\text { 1.1.3 Orientation ability } \\
\text { 1.1.4 Sense of safety }\end{array}$} & - $\quad$ Overview & not visible-visible \\
\hline & & - $\quad$ Safety & dangerous-safe \\
\hline 1.2 Sociological & 1.2.1 Land use & - $\quad$ Usage intensity & not visit-always visit \\
\hline \multirow[b]{2}{*}{ 1.3 Aesthetic-functional } & 1.3.1 Site aesthetic & - $\quad$ Space arrangement & disordered-ordered \\
\hline & 1.3.2 Artificial light effect & $\begin{array}{ll}\text { - } & \text { Fascination } \\
\text { - } & \text { Comfort } \\
\text { - } & \text { Compliance }\end{array}$ & $\begin{array}{l}\text { not fascinating-fascinating } \\
\text { comfortable glare-uncomfortable glare } \\
\text { incompatible-compatible }\end{array}$ \\
\hline
\end{tabular}

\section{The Experiment}

The model was used to evaluate different spatial conditions with different urban background. An important aspect was the inclusion of the time component (day and night evaluation). Lighting quality in a given location was evaluated indirectly by examining the perceived effect of all light sources on users. Lighting efficiency was expressed as the compliance of environmental perception and spatial utilization during day and night. The empirical research was based on a descriptive and causal experimental method. The experiment involved a sample of 200 participants, 100 men and 100 women aged 18 to 35 years. All participants were students at the University of Maribor in Slovenia in various fields of study. The participants were anonymous. The experiment was conducted in small groups of up to fifteen people. All participants were familiar with all the research sites, as they all visited them before the experiment started. The questionnaire was filled out in the classroom. To support memory, large-format images of each site were projected onto the wall to help the respondents remember and relive the environment. The experiment and data evaluation lasted in the time interval between 2015 and 2018.

The second largest Slovenian city was chosen as the research location. Maribor has an important central regional role in the traditional region of Lower Styria. The city preserves the awareness of its exceptional natural and geographical location. It is situated between the slopes of the hills Piramida and Kalvarija and the Mestni vrh (Town peak) in the north and the south side of the Alps, Pekrska gorca, and Pohorje. The Drava River leaves its alpine character here and becomes calmer as it enters the flat Pannonian plan. The Drava as a dividing line in the city has become an important focal point of the urban ambience [69]. The city center on the left bank of the river consists of a number of squares in the old core of the historical center, churches, monuments, and historical facades. The right bank of the river has mainly residential and industrial functions.

The selection of study sites focused primarily on basic urban typologies, such as: Street, square, and city park. The final choice of the study site was based on criteria such as: Urban characteristics, lighting infrastructure, type of lighting, lighting characteristics, lighting effect, illuminance, and color of lighting (Table 3). Based on the city matrix, ten specific sites were selected according to diversity principles. It was assumed that the centrally located areas on the left bank of the river are better known to the respondents. 
The following sites were selected: Gosposka Street (SITE 1), Poštna Street (SITE 2), Kneza Koclja -Street (SITE 3), Lent-Historic Town (SITE 4), Leon Štukelj Square (SITE 5), Castle Square (SITE 6), Main Square (SITE 7), Liberty square (SITE 8), and Slomšek Square (SITE 9) in City Park Maribor (SITE 10). The spatial distribution of the selected sites is shown in Figure 1. All selected sites are detailed in the Supplementary Materials (Tables S1-S10). Basically, the broad spectrum of different urban environments was selected on the basis of seven selection criteria (Table 3).

Table 3. Criteria and elements used in selecting study sites.

\begin{tabular}{|c|c|}
\hline Selection Criteria & Elements \\
\hline Urban characteristics & $\begin{array}{l}\text { - Urban typology: Street (main, side, transit); square (greenery on it, no greenery on it); green area } \\
\text { (city park) } \\
\text { - Spatial elements: Path, edge, district, node, landmark }\end{array}$ \\
\hline Lighting purpose & $\begin{array}{l}\text { - Street lighting, sidewalk lighting, architectural lighting, decorative lighting, commercials lighting, } \\
\text { security lighting, etc. }\end{array}$ \\
\hline Lighting infrastructure & $\begin{array}{l}\text { - Freestanding lamp (on a pole), wall lamp, pendant lamp, floor lamp, interior lighting of the building } \\
\text { (shop window), lighting of objects (information boards, billboards, road signs, etc.), light beam, etc. } \\
\text { - One-sided installation of lights, two-sided installation of lights }\end{array}$ \\
\hline Type of lights & - $\quad$ Mercury lamp, halogen lamp, sodium lamp, LED \\
\hline Lighting characteristics & $\begin{array}{l}\text { - } \quad \text { Direct and indirect distribution of luminous flux } \\
\text { - } \quad \text { Point and surface distribution of light }\end{array}$ \\
\hline Lighting effect & - Increase safety, visual guidance (orientation), information, warning, decoration, etc. \\
\hline Illuminance intensity & - $\quad$ Low, medium, high intensity (lux) \\
\hline Lighting color & $\begin{array}{l}\text { - Cool colors, warm colors } \\
\text { - Cande light (1800 k), Extra Warm White (2800 k), Warm White (3000 k), Cool White (4000 k), } \\
\text { Daylight (5000 k), Overcast Sky (6500-7500 k), Blue Sky (8000 k-12,000 k) }\end{array}$ \\
\hline
\end{tabular}

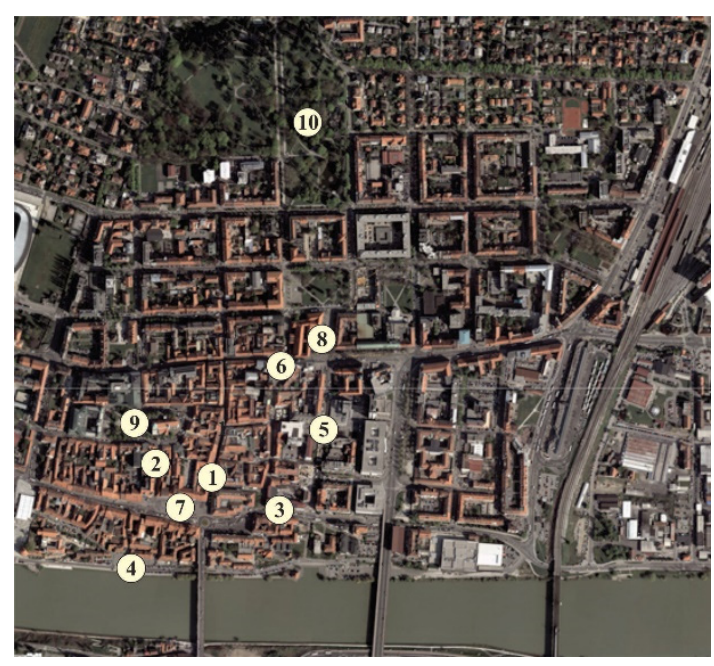

Figure 1. Spatial arrangement of selected study sites (orthophoto map: Geopedija, 2020). Legend: 1(Gosposka Street), 2 (Poštna Street) 3 (Kneza Koclja Street), 4 (Lent), 5 (Leon Štukelj Square), 6 (Castle Square), 7 (Main Square), 8 (Liberty Square), 9 (Slomšek Square) in 10 (City Park Maribor).

\section{Research Results of Artificial Night Light Impact}

The data collected on the basis of a questionnaire were statistically processed and analyzed using Statistical Product and Service Solutions (IBM SPSS Statistics). Methods of descriptive statistics (frequency and numerical analysis, arithmetic mean of the difference between mean and standard deviation) and inferential statistics (t-test for dependent samples and Pearson correlation coefficient $r$ ) were used. 


\subsection{Effects of Artificial Night Lighting Based on a Psychological Factor}

First of all, respondents assessed the presented sites on the basis of a psychological factor. Corresponding indicators of the SEC model are: individual feeling, attracting attention, orientation ability, and sense of safety. The respondents assessed the associated aspects of attraction, pleasantness, relaxation, composition, arousing interest, stimulation, overview, and safety on the basis of a five-level evaluation scale. The question on the questionnaire was, "Imagine that you are in the place indicated. Judge the scene. Circle the value between the two extreme terms that most closely matches your opinion." Respondents chose between two extremes, such as: (1) Not attractive-(5) attractive, (1) unpleasant-(5) pleasant, (1) tense-(5) relaxed, (1) simple-(5) complex, (1) boring-(5) interesting, (1) not arousing-(5) arousing, (1) not visible-(5) visible, and lastly, (1) dangerous-(5) safe. The number 3 represents the mean (e.g., neither unattractive nor attractive). The results of the comparative evaluations of the individual aspects for day and night are shown in Tables 4-7.

Table 4. Descriptive measurements of the indicator "individual feeling", the results of the $t$-test and the correlation for the dependent sample pair day-night.

\begin{tabular}{|c|c|c|c|c|c|c|c|c|}
\hline \multirow{2}{*}{ SITE } & \multicolumn{2}{|l|}{ DAY } & \multicolumn{2}{|c|}{ NIGHT } & \multirow{2}{*}{$\begin{array}{l}\text { Difference } \\
\bar{x}_{D}-\bar{x}_{N}\end{array}$} & \multirow{2}{*}{$t$} & \multirow{2}{*}{$2 p$} & \multirow{2}{*}{$r$} \\
\hline & $\bar{x}_{D}$ & $\sigma$ & $\bar{x}_{N}$ & $\sigma$ & & & & \\
\hline \multicolumn{9}{|c|}{ Attraction } \\
\hline SITE-1 & 3.10 & 0.857 & 3.06 & 1.043 & 0.045 & 0.510 & 0.610 & 0.151 \\
\hline SITE-2 & 3.64 & 0.957 & 2.85 & 1.220 & 0.795 & 8.284 & 0.000 * & 0.240 \\
\hline SITE-3 & 3.72 & 0.925 & 3.36 & 1.013 & 0.360 & 4.471 & 0.000 & 0.312 \\
\hline SITE-4 & 4.42 & 0.804 & 3.08 & 1.127 & 1.335 & 14.348 & 0.000 & 0.102 \\
\hline SITE-5 & 4.23 & 0.889 & 4.18 & 0.910 & 0.055 & 0.783 & 0.435 & 0.391 \\
\hline SITE-6 & 4.16 & 0.779 & 3.50 & 0.874 & 0.660 & 9.581 & 0.000 & 0.310 \\
\hline SITE-7 & 3.89 & 0.801 & 3.43 & 0.871 & 0.465 & 6.843 & 0.000 & 0.341 \\
\hline SITE-8 & 3.78 & 0.983 & 2.16 & 0.979 & 1.620 & 19.774 & 0.000 & 0.303 \\
\hline SITE-9 & 4.33 & 0.809 & 3.59 & 0.979 & 0.745 & 11.017 & 0.000 & 0.441 \\
\hline SITE-10 & 4.41 & 0.790 & 4.00 & 1.025 & 0.410 & 4.688 & 0.000 & 0.089 \\
\hline \multicolumn{9}{|c|}{ Pleasantness } \\
\hline SITE-1 & 3.25 & 1.025 & 2.89 & 0.966 & 0.355 & 3.776 & 0.000 & 0.109 \\
\hline SITE-2 & 3.74 & 0.959 & 2.91 & 1.214 & 0.830 & 9.401 & 0.000 & 0.350 \\
\hline SITE-3 & 3.72 & 0.984 & 3.37 & 0.952 & 0.350 & 4.253 & 0.000 & 0.278 \\
\hline SITE-4 & 4.37 & 0.858 & 2.95 & 1.138 & 1.415 & 15.077 & 0.000 & 0.137 \\
\hline SITE-5 & 4.16 & 0.833 & 4.25 & 0.747 & -0.090 & -1.445 & 0.150 & 0.383 \\
\hline SITE-6 & 4.15 & 0.804 & 3.48 & 0.879 & 0.665 & 9.713 & 0.000 & 0.341 \\
\hline SITE-7 & 3.89 & 0.775 & 3.39 & 0.884 & 0.445 & 6.195 & 0.000 & 0.256 \\
\hline SITE-8 & 3.64 & 0.957 & 2.23 & 1.044 & 1.415 & 15.718 & 0.000 & 0.192 \\
\hline SITE-9 & 4.34 & 0.753 & 3.59 & 0.941 & 0.750 & 10.812 & 0.000 & 0.346 \\
\hline SITE-10 & 4.40 & 0.814 & 3.92 & 1.063 & 0.480 & 5.683 & 0.000 & 0.211 \\
\hline \multicolumn{9}{|c|}{ Relaxation } \\
\hline SITE-1 & 3.18 & 0.843 & 2.89 & 0.822 & 0.295 & 3.954 & 0.000 & 0.195 \\
\hline SITE-2 & 3.54 & 0.929 & 2.84 & 1.029 & 0.695 & 8.193 & 0.000 & 0.253 \\
\hline SITE-3 & 3.57 & 0.900 & 3.28 & 0.820 & 0.290 & 3.695 & 0.000 & 0.170 \\
\hline SITE-4 & 4.22 & 0.966 & 3.06 & 1.117 & 1.160 & 12.250 & 0.000 & 0.180 \\
\hline SITE-5 & 3.91 & 0.894 & 4.03 & 0.921 & -0.120 & -1.799 & 0.074 & 0.460 \\
\hline SITE-6 & 3.90 & 0.835 & 3.33 & 0.827 & 0.565 & 7.987 & 0.000 & 0.276 \\
\hline SITE-7 & 3.61 & 0.896 & 3.30 & 0.783 & 0.050 & 4.062 & 0.000 & 0.206 \\
\hline SITE-8 & 3.55 & 0.917 & 2.37 & 0.963 & 1.180 & 14.339 & 0.000 & 0.235 \\
\hline SITE-9 & 4.23 & 0.794 & 3.41 & 0.957 & 0.825 & 11.074 & 0.000 & 0.287 \\
\hline SITE-10 & 4.44 & 0.787 & 3.67 & 1.103 & 0.770 & 8.622 & 0.000 & 0.139 \\
\hline
\end{tabular}

$\bar{x}$ : Arithmetic mean; $\sigma$ : Standard deviation; $\mathrm{t}$ : Value difference arithmetic test; $2 p$ : Bidirectional level of statistical significance; $r$ : Pearson product-moment correlation coefficient; ${ }^{*} p<0.001$ for all the 0.000 values. Legend: SITE-1 (Gosposka Street), SITE-2 (Poštna Street), SITE-3 (Kneza Koclja Street), SITE-4 (Lent), SITE-5 (Leon Štukelj Square), SITE-6 (Castle Square), SITE-7 (Main Square), SITE-8 (Liberty Square), SITE-9 (Slomšek Square) in SITE-10 (City Park Maribor). 
Based on the arithmetic mean of the indicator individual feeling, the locations are very different (Table 4). The average ratings during the day range from 3.10 at SITE-1 (Gosposka Street) for the attraction aspect to 4.44 at SITE-10 (Maribor City Park) for the relaxation aspect. The values of the indicators at night are in most cases lower, ranging from 2.16 at SITE-8 (Liberty square) for the attraction aspect to 4.25 at SITE-5 (Leon Štukelj Square) for the comfort aspect. The standard deviation varies within the range of 0.753 to 1.025 for the daytime ratings and within the range of 0.783 to 1.220 for the night ratings. It can be seen that the standard deviation is slightly smaller at higher averages compared to lower averages, which means that respondents' ratings are less diffuse at higher averages. A comparative analysis between day and night shows that in most cases of the sites and for almost all aspects, the arithmetic mean values for the day were higher than for the night. Outstanding locations where there are no statistically significant differences are SITE-1 (Gosposka Street) and SITE-5 (Leon Štukelj Square) with regard to the aspect of attraction and SITE-5 (Leon Štukelj Square) with regard to the aspect of comfort and relaxation.

Table 5. Descriptive measurements of the indicator "attracting attention", the results of the $t$-test and the correlation for the dependent sample pair day-night.

\begin{tabular}{|c|c|c|c|c|c|c|c|c|}
\hline \multirow{2}{*}{ SITE } & \multirow{2}{*}{$\begin{array}{l}\text { DAY } \\
\bar{x}_{D}\end{array}$} & \multicolumn{3}{|c|}{ NIGHT } & \multirow{2}{*}{$\begin{array}{l}\text { Difference } \\
\bar{x}_{D}-\bar{x}_{N}\end{array}$} & \multirow{2}{*}{$t$} & \multirow{2}{*}{$2 p$} & \multirow{2}{*}{$r$} \\
\hline & & $\sigma$ & $\bar{x}_{N}$ & $\sigma$ & & & & \\
\hline \multicolumn{9}{|c|}{ Composition } \\
\hline SITE-1 & 2.57 & 1.005 & 2.86 & 1.004 & -0.285 & -3.289 & 0.001 & 0.256 \\
\hline SITE-2 & 2.66 & 1.005 & 2.27 & 1.003 & -0.060 & -0.681 & 0.497 & 0.229 \\
\hline SITE-3 & 2.80 & 1.051 & 2.68 & 0.868 & 0.125 & 1.535 & 0.126 & 0.292 \\
\hline SITE-4 & 2.64 & 1.099 & 2.59 & 0.973 & 0.050 & 0.529 & 0.597 & 0.172 \\
\hline SITE-5 & 3.08 & 1.166 & 3.12 & 1.167 & -0.040 & -0.452 & 0.652 & 0.425 \\
\hline SITE-6 & 3.00 & 1.080 & 2.76 & 0.840 & 0.240 & 3.154 & 0.002 & 0.393 \\
\hline SITE-7 & 2.94 & 1.037 & 2.74 & 0.816 & 0.195 & 2.569 & 0.011 & 0.348 \\
\hline SITE-8 & 2.97 & 1.084 & 2.48 & 1.046 & 0.490 & 5.055 & $0.000 *$ & 0.172 \\
\hline SITE-9 & 2.85 & 1.126 & 2.89 & 0.986 & -0.045 & -0.516 & 0.606 & 0.324 \\
\hline SITE-10 & 2.61 & 1.190 & 2.67 & 1.052 & -0.060 & -0.616 & 0.538 & 0.250 \\
\hline \multicolumn{9}{|c|}{ Arouse interest } \\
\hline SITE-1 & 2.89 & 0.963 & 2.94 & 1.011 & -0.055 & -0.580 & 0.563 & 0.076 \\
\hline SITE-2 & 3.47 & 0.992 & 2.86 & 1.171 & 0.615 & 6.823 & 0.000 & 0.314 \\
\hline SITE-3 & 3.57 & 0.975 & 3.17 & 0.996 & 0.400 & 4.607 & 0.000 & 0.224 \\
\hline SITE-4 & 4.06 & 0.922 & 2.94 & 1.061 & 1.125 & 12.174 & 0.000 & 0.137 \\
\hline SITE-5 & 4.09 & 0.941 & 4.25 & 0.813 & -0.160 & -2.323 & 0.021 & 0.391 \\
\hline SITE-6 & 3.90 & 0.902 & 3.17 & 0.936 & 0.730 & 9.573 & 0.000 & 0.312 \\
\hline SITE-7 & 3.65 & 0.896 & 3.12 & 0.990 & 0.525 & 6.573 & 0.000 & 0.286 \\
\hline SITE-8 & 3.65 & 1.075 & 2.09 & 0.936 & 1.555 & 16.889 & 0.000 & 0.167 \\
\hline SITE-9 & 4.06 & 0.889 & 3.61 & 0.939 & 0.450 & 6.115 & 0.000 & 0.353 \\
\hline SITE-10 & 4.04 & 0.918 & 3.95 & 0.993 & 0.095 & 1.168 & 0.244 & 0.278 \\
\hline \multicolumn{9}{|c|}{ Stimulation } \\
\hline SITE-1 & 2.87 & 0.933 & 2.95 & 0.963 & -0.080 & -0.831 & 0.407 & -0.031 \\
\hline SITE-2 & 3.32 & 0.936 & 2.78 & 1.122 & 0.540 & 6.007 & 0.000 & 0.248 \\
\hline SITE-3 & 3.43 & 0.938 & 3.14 & 0.981 & 0.295 & 3.611 & 0.000 & 0.275 \\
\hline SITE-4 & 3.70 & 1.076 & 2.74 & 0.999 & 0.955 & 9.844 & 0.000 & 0.127 \\
\hline SITE-5 & 3.84 & 0.939 & 4.10 & 0.862 & -0.265 & -3.693 & 0.000 & 0.386 \\
\hline SITE-6 & 3.69 & 0.889 & 2.96 & 0.870 & 0.730 & 9.615 & 0.000 & 0.255 \\
\hline SITE-7 & 3.41 & 0.851 & 3.05 & 0.928 & 0.355 & 4.555 & 0.000 & 0.235 \\
\hline SITE-8 & 3.42 & 0.926 & 2.13 & 0.958 & 1.290 & 15.804 & 0.000 & 0.250 \\
\hline SITE-9 & 3.78 & 0.980 & 3.42 & 0.960 & 0.340 & 4.106 & 0.000 & 0.277 \\
\hline SITE-10 & 3.83 & 1.061 & 3.74 & 1.091 & 0.095 & 1.011 & 0.313 & 0.239 \\
\hline
\end{tabular}

$\bar{x}$ : Arithmetic mean; $\sigma$ : Standard deviation; t: value difference arithmetic test; $2 p$ : Bidirectional level of statistical significance; $r$ : Pearson product-moment correlation coefficient; ${ }^{*} p<0.001$ for all the 0.000 values. Legend: SITE-1 (Gosposka Street), SITE-2 (Poštna Street), SITE-3 (Kneza Koclja Street), SITE-4 (Lent), SITE-5 (Leon Štukelj Square), SITE-6 (Castle Square), SITE-7 (Main Square), SITE-8 (Liberty Square), SITE-9 (Slomšek Square) in SITE-10 (City Park Maribor). 
SITE-5 (Leon Štukelj Square) is particularly striking because the aspects of pleasantness and relaxation have higher arithmetic averages for the night than for the day. The aspect of pleasantness is not statistically significant because $p>0.05$. There are larger differences in the aspect of relaxation. Here we are already very close to statistical significance, where the bilateral $\mathrm{p}(2 p=0.074)$ is greater than 0.005 . If we were to look in only one direction, we could even speak of a statistically significant difference. The correlation coefficient $r$ lies in the interval between 0.012 and 0.460 (rarely exceeds the value of 0.4 ), which usually indicates a weak correlation relationship for day and night.

The indicator attracting attention consists of three aspects: Composition, arouse interest, and stimulation. Compared to the individual feeling indicator, the indicator attracting attention has a lower arithmetic mean value both during the day and at night. The arithmetic mean is between 2.57 and 4.09 during the day and 2.13 and 4.25 at night. The response dispersion is also greater in both observation periods. The standard deviation varies from 0.851 to 1.190 during the day and from 0.813 to 1.171 at night. A negative average difference means in some cases that the site received higher sympathy levels during the night. We have the highest negative difference -0.285 at SITE-1 (Gosposka Street) for the aspect of composition. This difference is statistically significant. SITE-5 (Leon Štukelj square) has a statistically significant difference for two aspects: Arousing interest and stimulation. On other locations, where we received higher ratings for the night than for the day, the difference in rating is not statistically significant. These are the sites: SITE-2 (Poštna Street), SITE-5 (Leon Štukelj Square), SITE-9 (Slomšek Square), and SITE-10 (Maribor City Park) for the aspect of composition and SITE-1 (Gosposka Street) for the aspect of arousing interest and stimulation. For locations that received a higher arithmetic average, we have the highest score of 1.25 at SITE- 4 (Lent) for the aspect of arousing interest. For the aspect of composition, SITE-6 (Castle Square), SITE-7 (Main Square), and SITE-8 (Trg Svobode) have higher arithmetic mean scores for the day than for the night. These differences are statistically significant. As far as arousing interest is concerned, in most cases the locations have higher average values for the day than for the night. The statistical difference is not significant only for SITE-1 (Gosposka Street) and SITE-10 (Maribor City Park). A more or less identical situation was found when evaluating the stimulation aspect. The correlation coefficient indicates a weak or moderate correlation.

SITE-5 (Leon Štukelj square) is again particularly striking. The aspect composition has a relatively high correlation coefficient $r=0.425$ of moderate correlation. The results of the $t$-test $(t=-0.452$ and $2 p=0.652)$ show that there are no statistically significant differences between the two mean values $(-0.040)$. This result indicates a moderately consistent distribution of responses for day and night, although the difference in the mean value is very small.

Table 6. Descriptive measurements of the indicator "orientation ability", the results of the $t$-test and the correlation for the dependent sample pair day-night.

\begin{tabular}{|c|c|c|c|c|c|c|c|c|}
\hline \multirow{2}{*}{ SITE } & \multicolumn{2}{|l|}{ DAY } & \multicolumn{2}{|c|}{ NIGHT } & \multirow{2}{*}{$\begin{array}{l}\text { Difference } \\
\bar{x}_{D}-\bar{x}_{N}\end{array}$} & \multirow{2}{*}{$t$} & \multirow{2}{*}{$2 p$} & \multirow{2}{*}{$r$} \\
\hline & $\bar{x}_{D}$ & $\sigma$ & $\bar{x}_{N}$ & $\sigma$ & & & & \\
\hline \multicolumn{9}{|c|}{ Overview } \\
\hline SITE-1 & 3.55 & 1.031 & 3.29 & 0.906 & 0.260 & 2.771 & 0.006 & 0.065 \\
\hline SITE-2 & 3.71 & 0.906 & 2.79 & 1.115 & 0.920 & 9.801 & 0.000 * & 0.148 \\
\hline SITE-3 & 4.16 & 0.845 & 3.76 & 0.915 & 0.395 & 5.291 & 0.000 & 0.282 \\
\hline SITE-4 & 4.31 & 0.817 & 2.86 & 1.152 & 1.450 & 14.772 & 0.000 & 0.036 \\
\hline SITE-5 & 4.44 & 0.713 & 4.40 & 0.679 & 0.045 & 0.774 & 0.440 & 0.303 \\
\hline SITE-6 & 4.14 & 0.796 & 3.65 & 0.890 & 0.490 & 7.287 & 0.000 & 0.368 \\
\hline SITE-7 & 4.11 & 0.735 & 3.58 & 0.870 & 0.530 & 7.300 & 0.000 & 0.190 \\
\hline SITE-8 & 3.98 & 0.910 & 2.12 & 1.028 & 1.860 & 20.302 & 0.000 & 0.110 \\
\hline SITE-9 & 3.71 & 1.083 & 3.31 & 1.039 & 0.395 & 4.434 & 0.000 & 0.296 \\
\hline SITE-10 & 4.21 & 0.848 & 3.52 & 1.027 & 0.690 & 8.460 & 0.000 & 0.255 \\
\hline
\end{tabular}

$\bar{x}$ : Arithmetic mean; $\sigma$ : Standard deviation; $t$ : Value difference arithmetic test; $2 p$ : Bidirectional level of statistical significance; $r$ : Pearson product-moment correlation coefficient; ${ }^{*} p<0.001$ for all the 0.000 values. Legend: SITE-1(Gosposka Street), SITE-2 (Poštna Street), SITE-3 (Kneza Koclja Street), SITE-4 (Lent), SITE-5 (Leon Štukelj Square), SITE-6 (Castle Square), SITE-7 (Main Square), SITE-8 (Liberty Square), SITE-9 (Slomšek Square) in SITE-10 (City Park Maribor). 
"Orientation ability" is an indicator where higher or better ratings are expected for daytime compared to night time (Table 6). We have a minimal difference in average estimates at SITE-5 (Leon Štukelj square). On this outstanding location, we did not find any statistically relevant difference between the average ratings for night and day (average difference $=0.045, t=0.774$ and $2 p=0.440$ ). In general, the arithmetic mean values for the day (from 3.55 to 4.44 ) are higher than for the night (from 2.12 to 4.40 ).

Table 7. Descriptive measurements of the indicator "sense of safety", the results of the t-test and the correlation for the dependent sample pair day-night.

\begin{tabular}{|c|c|c|c|c|c|c|c|c|}
\hline \multirow{2}{*}{ SITE } & \multicolumn{2}{|c|}{ DAY } & \multicolumn{2}{|c|}{ NIGHT } & \multirow{2}{*}{$\begin{array}{l}\text { Difference } \\
\bar{x}_{D}-\bar{x}_{N}\end{array}$} & \multirow{2}{*}{$t$} & \multirow{2}{*}{$2 p$} & \multirow{2}{*}{$r$} \\
\hline & $\bar{x}_{D}$ & $\sigma$ & $\bar{x}_{N}$ & $\sigma$ & & & & \\
\hline \multicolumn{9}{|c|}{ Sense of safety } \\
\hline SITE-1 & 3.81 & 1.720 & 3.13 & 0.963 & 0.680 & 8.057 & $0.000 *$ & 0.316 \\
\hline SITE-2 & 3.82 & 0.910 & 2.78 & 1.152 & 1.035 & 11.751 & 0.000 & 0.293 \\
\hline SITE-3 & 3.73 & 0.960 & 3.44 & 0.895 & 0.290 & 3.665 & 0.000 & 0.274 \\
\hline SITE-4 & 3.74 & 1.024 & 2.65 & 1.111 & 1.095 & 12.151 & 0.000 & 0.290 \\
\hline SITE-5 & 4.19 & 0.829 & 4.13 & 0.814 & 0.065 & 1.012 & 0.313 & 0.389 \\
\hline SITE-6 & 4.14 & 0.833 & 3.44 & 0.883 & 0.700 & 9.458 & 0.000 & 0.257 \\
\hline SITE-7 & 3.79 & 0.842 & 3.30 & 0.919 & 0.490 & 6.913 & 0.000 & 0.355 \\
\hline SITE-8 & 3.89 & 0.878 & 2.25 & 1.025 & 1.654 & 19.212 & 0.000 & 0.198 \\
\hline SITE-9 & 4.14 & 0.874 & 3.29 & 1.000 & 0.850 & 11.003 & 0.000 & 0.327 \\
\hline SITE-10 & 4.00 & 1.022 & 3.25 & 1.189 & 0.750 & 8.505 & 0.000 & 0.372 \\
\hline
\end{tabular}

$\bar{x}$ : Arithmetic mean; $\sigma$ : Standard deviation; $t$ : Value difference arithmetic test; $2 p$ : Bidirectional level of statistical significance; $r$ : Pearson product-moment correlation coefficient; ${ }^{*} p<0.001$ for all the 0.000 values. Legend: SITE-1 (Gosposka Street), SITE-2 (Poštna Street), SITE-3 (Kneza Koclja Street), SITE-4 (Lent), SITE-5 (Leon Štukelj Square), SITE-6 (Castle Square), SITE-7 (Main Square), SITE-8 (Liberty Square), SITE-9 (Slomšek Square) in SITE-10 (City Park Maribor).

We have a similar picture as with the indicator "orientation ability" with the indicator "sense of safety". The arithmetic mean for the day (from 3.73 to 4.19 ) is higher in all cases compared to the night (from 2.25 to 4.13 ). A special feature is again SITE-5, where the difference is not statistically significant (difference of averages $=0.065, t=1.012$ and $2 p=0.313)$. The respondents felt that this location was equally safe by day and night.

\subsection{Effects of Artificial Night Lighting Based on a Sociological Factor}

The "sociological factor" is assessed on the basis of the indicator land use and corresponding aspects of "usage intensity". Respondents rated the frequency of site visits using a five-level evaluation scale (e.g., (1) do not visit, (3) neither do not visit nor visit, (5) always visit). The research question asked, "How often do you visit the site during the day/night?" It was assumed that the higher frequency of visits means an increased range of activities (walking, sitting, socializing, playing, cycling, skateboarding, roller-skating, sightseeing, etc.) that are carried out there. The results of both time sequences are shown in Table 8.

The results in Table 8 show that the individual sites vary greatly in terms of the frequency of visits. During the day, these are the sites that are visited most frequently: Slomšek Square (3.61), Main Square (3.43), and Gosposka Street (3.13). In addition, at night, the number of visits to individual locations varies considerably and is lower in all locations at the level of statistically significant differences compared to the time of day. It is lowest in the same two places as during the day. These are Kneza Koclja street (1.83) and Maribor City Park (1.77). The frequency of visits to each location varies during the day and night. At night are the most frequently visited places: Lent (2.59), Main Square (2.53), Slomšek Square (2.52), and Poštna Street (2.40). 
Table 8. Descriptive measurements of the indicator "land use" and the results of the t-test and correlation for dependent samples of the pairs day-night.

\begin{tabular}{|c|c|c|c|c|c|c|c|c|}
\hline \multirow{2}{*}{ SITE } & \multirow{2}{*}{$\begin{array}{l}\text { DAY } \\
\bar{x}_{D}\end{array}$} & \multicolumn{3}{|c|}{ NIGHT } & \multirow{2}{*}{$\begin{array}{l}\text { Difference } \\
\bar{x}_{D}-\bar{x}_{N}\end{array}$} & \multirow{2}{*}{$t$} & \multirow{2}{*}{$2 p$} & \multirow{2}{*}{$r$} \\
\hline & & $\sigma$ & $\bar{x}_{N}$ & $\sigma$ & & & & \\
\hline \multicolumn{9}{|c|}{ Usage intensity } \\
\hline SITE-1 & 3.13 & 1.140 & 2.32 & 1.055 & 0.815 & 11.609 & 0.000 * & 0.590 \\
\hline SITE-2 & 3.06 & 1.189 & 2.40 & 1.173 & 0.665 & 8.590 & 0.000 & 0.570 \\
\hline SITE-3 & 2.36 & 1.098 & 1.83 & 0.882 & 0.535 & 9.028 & 0.000 & 0.662 \\
\hline SITE-4 & 3.06 & 1.048 & 2.59 & 1.126 & 0.465 & 7.038 & 0.000 & 0.633 \\
\hline SITE-5 & 2.89 & 1.138 & 2.20 & 1.047 & 0.690 & 10.072 & 0.000 & 0.609 \\
\hline SITE-6 & 2.99 & 1.188 & 2.22 & 1.046 & 0.770 & 12.827 & 0.000 & 0.718 \\
\hline SITE-7 & 3.43 & 1.054 & 2.53 & 1.116 & 0.900 & 12.696 & 0.000 & 0.574 \\
\hline SITE-8 & 2.75 & 1.124 & 2.10 & 0.977 & 0.650 & 10.606 & 0.000 & 0.668 \\
\hline SITE-9 & 3.61 & 1.227 & 2.52 & 1.160 & 1.085 & 13.648 & 0.000 & 0.558 \\
\hline SITE-10 & 2.62 & 1.035 & 1.77 & 0.895 & 0.850 & 11.716 & 0.000 & 0.442 \\
\hline
\end{tabular}

$\bar{x}$ : Arithmetic mean; $\sigma$ : Standard deviation; $t$ : Value difference arithmetic test; $2 p$ : Bidirectional level of statistical significance; $r$ Pearson product-moment correlation coefficient; ${ }^{*} p<0.001$ for all the 0.000 values. Legend: SITE-1 (Gosposka Street), SITE-2 (Poštna Street), SITE-3 (Kneza Koclja Street), SITE-4 (Lent), SITE-5 (Leon Štukelj Square), SITE-6 (Castle Square), SITE-7 (Main Square), SITE-8 (Liberty Square), SITE-9 (Slomšek Square) in SITE-10 (City Park Maribor).

The correlation coefficient $r$ ranges from 0.420 to 0.827 , which implies a moderate to predominantly high correlation between the distribution functions of the day and night estimates. The results show that the movement of the respondents is concentrated in the historical city center both during the day and at night. Places on the outskirts of the city are visited less frequently in both periods. The greatest difference in the frequency of visits during the day and at night is found at Slomšek Square (1085). The results indicate that this site is an important transit node and is used only during the day as a place for emergency activities.

\subsection{Effects of Artificial Night Lighting Based on a Aesthetic-Functional Factor}

On the basis of the Aesthetic-Functional factor, the respondents evaluated the indicators: "site aesthetic" and "artificial light effect". The following aspects were used: "space arrangement", "fascination", "comfort", and "compliance", and they were evaluated on the basis of a five-level evaluation scale. The questionnaire contained two questions.

The first was, "Imagine that you are in the place indicated. Evaluate the scene." Respondents chose between two extremes, such as: (1) Disordered-(5) ordered. The number 3 represents the mean.

The second task was "Evaluate light effect". Respondents chose between two extremes, such as: (1) Not fascinating-(5) fascinating, (1) uncomfortable glare-(5) comfortable glare, and the last one (1) incompatible-(5) compatible. The number 3 represents the mean. The results of the comparative evaluations for day and night are shown in Tables 9 and 10.

The indicator "site aesthetics" shows that the average score during the day (from 3.51 to 4.62 ) is higher than at night (from 2.73 to 4.44 ). These differences were statistically significant in all cases, except in the case of SITE-1 (Gosposka Street), where the difference in arithmetic mean is $0.110, t=1.395$ and $2 p=0.165$. This location has a relatively low value of the averages for both day and night (3.51 for day and 3.40 for night).

The artificial light effect indicator gives the arithmetic mean and standard deviation for the aspect's "fascination", "comfort", and "compliance". In our case, we have evaluated the artificial night light effect. We have not chosen to evaluate the daylight effect because daylight is not constant. It changes with the time of day or season and weather conditions. The average values range from 2.25 to 3.97 for the aspect of "comfort", from 1.71 to 4.47 for the aspect of "fascination" and from 2.09 to 4.33 for the aspect of "compliance". SITE-5 (Leon Štukelj Square) has the highest arithmetic mean in all categories and the lowest dispersion estimates. 
Table 9. Descriptive measurements of the indicator site aesthetic, the results of the t-test, and the correlation for the dependent sample pair day-night.

\begin{tabular}{|c|c|c|c|c|c|c|c|c|}
\hline \multirow{2}{*}{ SITE } & \multirow{2}{*}{$\begin{array}{l}\text { DAY } \\
\bar{x}_{D}\end{array}$} & \multicolumn{3}{|c|}{ NIGHT } & \multirow{2}{*}{$\begin{array}{l}\text { Difference } \\
\bar{x}_{D}-\bar{x}_{N}\end{array}$} & \multirow{2}{*}{$t$} & \multirow{2}{*}{$2 p$} & \multirow{2}{*}{$r$} \\
\hline & & $\sigma$ & $\bar{x}_{N}$ & $\sigma$ & & & & \\
\hline \multicolumn{9}{|c|}{ Space arrangement } \\
\hline SITE-1 & 3.51 & 0.924 & 3.40 & 0.908 & 0.110 & 1.395 & 0.165 & 0.259 \\
\hline SITE-2 & 3.71 & 0.801 & 3.12 & 1.020 & 0.585 & 7.686 & $0.000 *$ & 0.320 \\
\hline SITE-3 & 4.44 & 0.747 & 3.87 & 0.881 & 0.565 & 7.987 & 0.000 & 0.254 \\
\hline SITE-4 & 3.91 & 0.975 & 3.32 & 1.006 & 0.585 & 7.433 & 0.000 & 0.369 \\
\hline SITE-5 & 4.62 & 0.581 & 4.44 & 0.684 & 0.185 & 3.976 & 0.000 & 0.469 \\
\hline SITE-6 & 4.09 & 0.765 & 3.71 & 0.788 & 0.385 & 6.460 & 0.000 & 0.411 \\
\hline SITE-7 & 3.91 & 0.863 & 3.67 & 0.752 & 0.245 & 3.805 & 0.000 & 0.371 \\
\hline SITE-8 & 3.82 & 0.946 & 2.73 & 1.037 & 1.090 & 13.176 & 0.000 & 0.306 \\
\hline SITE-9 & 4.18 & 0.798 & 3.74 & 0.859 & 0.440 & 6.668 & 0.000 & 0.368 \\
\hline SITE-10 & 4.17 & 0.907 & 4.00 & 0.851 & 0.165 & 2.118 & 0.035 & 0.215 \\
\hline
\end{tabular}

$\bar{x}$ : Arithmetic mean; $\sigma$ : Standard deviation; $t$ : Value difference arithmetic test; $2 p$ : Bidirectional level of statistical significance; $r$ Pearson product-moment correlation coefficient; ${ }^{*} p<0.001$ for all the 0.000 values. Legend: SITE-1 (Gosposka Street), SITE-2 (Poštna Street), SITE-3 (Kneza Koclja Street), SITE-4 (Lent), SITE-5 (Leon Štukelj Square), SITE-6 (Castle Square), SITE-7 (Main Square), SITE-8 (Liberty Square), SITE-9 (Slomšek Square) in SITE-10 (City Park Maribor).

Table 10. Descriptive measurements of the indicator "artificial light effect" during the night-time.

\begin{tabular}{ccccccc}
\hline \multirow{2}{*}{ SITE } & \multicolumn{2}{c}{ Fascination } & \multicolumn{2}{c}{ Comfort } & \multicolumn{2}{c}{ Compliance } \\
\cline { 2 - 6 } & $\bar{x}_{F N}$ & $\sigma$ & $\bar{x}_{C T}$ & $\sigma$ & $\bar{x}_{C E}$ & $\sigma$ \\
\hline SITE-1 & 2.25 & 0.981 & 2.29 & 1.005 & 2.42 & 1.029 \\
SITE-2 & 3.08 & 0.924 & 2.33 & 1.170 & 2.53 & 1.164 \\
SITE-3 & 2.99 & 1.012 & 2.95 & 1.026 & 3.20 & 1.027 \\
SITE-4 & 3.00 & 0.995 & 2.33 & 1.071 & 3.02 & 1.150 \\
SITE-5 & 3.97 & 1.098 & 4.47 & 0.776 & 4.33 & 0.832 \\
SITE-6 & 3.01 & 0.962 & 2.59 & 1.048 & 2.87 & 1.055 \\
SITE-7 & 3.01 & 0.943 & 2.63 & 1.014 & 2.98 & 1.046 \\
SITE-8 & 2.63 & 0.937 & 1.71 & 0.884 & 2.09 & 1.023 \\
SITE-9 & 2.89 & 1.153 & 3.01 & 1.063 & 3.11 & 1.086 \\
SITE-10 & 3.59 & 1.057 & 3.55 & 1.124 & 3.67 & 1.086 \\
\hline
\end{tabular}

$\bar{x}$ : Arithmetic mean; $\sigma$ : Standard deviation. Legend: SITE-1 (Gosposka Street), SITE-2 (Poštna Street), SITE-3 (Kneza Koclja Street), SITE-4 (Lent), SITE-5 (Leon Štukelj Square), SITE-6 (Castle Square), SITE-7 (Main Square), SITE-8 (Liberty Square), SITE-9 (Slomšek Square) in SITE-10 (City Park Maribor).

\section{Discussion and Conclusions}

Artificial lighting is a specific design of a space, where it is important which spatial components should be made visible and emphasized, what the lighting effect should look like, what kind of light is used, where lighting elements can be placed, and last but not least, who is the user of the place. In today's cities, a multitude of different lighting arrangements are interwoven. Successful ones are those that, under certain circumstances, provide the best possible conditions that are the same for all user groups. Unsuccessful are those that do not at least meet the needs of one user group. In general, too much light or the wrong direction of light is a deficit in terms of spatial utilization, electricity consumption, and ecological acceptance. The strategy of artificial night lighting of cities must first be approached globally at city level and then locally at a specific site.

City lighting consists of various types such as street lighting, sidewalk lighting, architectural lighting, decorative lighting, security lighting, commercial lighting, etc. In the urban matrix, they usually do not occur independently, but intertwine with each other. Primary lighting is a technical discipline that, in addition to a strict technical approach based on measurable physical quantities, also requires the consideration of a subjective approach in which the psychological, sociological, and aesthetic functional aspect should 
not be neglected. This is understandable, since we are introducing the night light precisely for the users, to satisfy their needs. It would be right to take the user, his needs and the subjective aspect as a starting point. However, the perception of the environment is not universal. Such an attitude also requires the inclusion of a numeric to obtain comparable results. Nevertheless, one cannot speak of uniform units of measurement-the perception of the environment is perceived differently by different people.

The development of society and the growing demands of people mean that considering the quality of lighting only in terms of the need for safety is not sufficient. Therefore, the introduction of new criteria and methods for the evaluation of outdoor lighting is necessary. Moreover, the wide variety of outdoor lighting options in terms of lamps, luminaires, and their arrangement require the search for effective methods to select the most suitable outdoor lighting solution. A holistic approach is required. Today, a comprehensive environmental assessment is composed of lighting efficiency, energy efficiency, and ecoefficiency criteria.

In this paper, a method for evaluating the nocturnal environment was proposed. SEC model SEC methodology and the assessment tool (questionnaire) were developed step by step for this purpose using top-down approach. Initially, the SEC model was developed to evaluate the visual quality and visual potential of a particular place. This time, we examine the synergistic effects that can be achieved using the model. To demonstrate the flexibility of the SEC model and its applicability for a new purpose (lighting quality assessment), the model and methodology were upgraded. With this, the SEC model has already received partial verification. Such comprehensive space evaluation cannot be traced anywhere in the existing literature and therefore represents a contribution to science. Placing the SEC model in the context of new findings on sustainable city lighting makes the SEC methodology alive, current, and worth further research on the possibilities of its use. The SEC methodology is currently in the evolution phase and will be supplemented or improved in the future.

SEC methodology is effective in making cyclical evaluations, such as monitoring the effect of artificial night lighting over time, and in making analytical measurements before and after spatial interventions, such as lighting refurbishment at specific locations. Comparable assessment of visual arrangements affected by night light is possible at any location with different urban background. As demonstrated in the research, even a single application of the model provides us with information about the current state, unused environmental potentials, or the presence of excessive and unnecessary lighting, which causes energy loss and light pollution. In the present study, the option of single application was used.

Evaluation methodology was tested in environments with different urban backgrounds. The results of ten case studies with different urbanistic background are presented. Since we are focusing on the users, the entire model implementation was not required for the purpose of the research. To limit the scope, only the dimension "suitability to everyone", which includes the artificial lighting quality aspect from the user perspective, was used. Lighting quality at a given location was assessed indirectly by examining the perceived effect of all light sources on users. Lighting efficiency was expressed as compliance of environmental perception and spatial utilization during day and night. The subjective experience of open space during night time compared to daytime is an important category if we want to achieve lighting quality in the context of sustainable city lighting. A holistic assessment approach requires the inclusion of many indicators in addition to the "sense of safety", such as: "individual feeling", "attracting attention", "orientation ability", "land

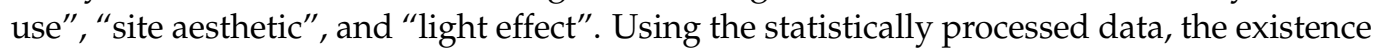
of differences in the subjective perception of urban open space during the day and night was demonstrated with a statistically relevant significance of $\mathrm{p}<0.05$. The hypothesis 1 (The users' perception of the environment and use of space is different during the day and at night) is confirmed. 
Development and application of the SEC methodology that could be applied all over the world also confirmed hypothesis 2 (By holistically assessing subjective indicators of lighting efficiency, it is possible to evaluate the impact of artificial night lighting in different urban open spaces). Due to the sample of 200 respondents (100 men, 100 women), the results can be within the limits of statistical confidence, generalized to the whole population between 18 and 30 years of age. The gained findings can at least be generalized to the entire population with similar life habits, and cultural and natural backgrounds, since such cities show a similar historical and geographical development.

Humans are mostly diurnal creatures, performing many activities on a daily basis. Of course, there are some exceptions, such as night shift workers, who may have a very different view of the night compared to the day. The age group of this study is limited. Future studies should be extended to also include the elderly. Their nocturnal perception and use of space might be different. However, so far, the results obtained are a good start, even if they were acquired in a single city on a group of university students.

If one compares the evaluation results of all sites, there is one site that stands out in almost all evaluated categories, which also reflects its local character. Site five (Leon Štukelj Square: SITE-5) is rated much higher than other sites. The discrepancies between day and night ratings are smaller. The results obtained indicate that this site received a higher environmental quality due to a higher lighting quality. The site was renovated in 2011, and these results indicate a successful renovation. In all other cases, action must be taken during the night to bring the visual impact of the site closer to the daylight ambience.

To this end, a new basic presumption for the quality of artificial night light should be established: Artificial lighting of urban open spaces is of high quality if the difference in spatial perception and utilization between day and night is as small as possible.

Received research results:

(1) Demonstrated relationship between sustainable city lightning and lighting quality;

(2) SEC methodology and SEC model placed in the context of new knowledge on sustainable city lighting;

(3) SEC model transformation and its application to new purpose (lighting quality evaluation) on locations with different urban backgrounds;

(4) proven influence of artificial night light on users' spatial perception;

(5) a proposal of a new basic presumption for artificial lighting quality; and

(6) confirmation of hypotheses.

These are original scientific contributions presented in this paper.

The application of SEC methodology in planning practice can lead to a reduction of energy waste and to the limitation of light pollution. In order to obtain a holistic picture of a city, it is necessary to disseminate the research via a wider ratio. More locations in the city are needed, not just locations tied to the city center. The article also presents the basic criteria for site selection and analysis. For the future it would be useful to develop an advanced methodology for site selection. A model verification at several locations with similar urban typology, such as streets, parks, and squares, would also provide new insights by comparing the results of same typology. In order to obtain proper knowledge of the larger geographical area, it is also recommended to extend the research to different geographical, cultural, and religious areas.

Supplementary Materials: The following are available online at https:/ / www.mdpi.com/2071-105 0/13/6/3409/s1, Supplementary materials consist of sites description (Tables S1-S10).

Funding: This research received no external funding.

Data Availability Statement: No applicable.

Acknowledgments: The author is grateful to the anonymous reviewers, who provided constructive comments on the earlier version of the paper.

Conflicts of Interest: The author declares no conflict of interest. 


\section{References}

1. Gregory, R.L. Eye and Brain, The Psychology of Seeing; Oxford University Press: Oxford, UK, 1998.

2. Kralikova, R.; Pinosova, M.; Hricova, B. Lighting Quality and its effects on productivity and human healts. Int. J. Interdiscip. Theory Pract. 2016, 10, 8-12.

3. Lynch, K. Image of the City; Institute of Technology: Cambridge, UK, 1960.

4. Huber, C. Sicherheit durch Licht. Str. Verk. 2006, 9, 6-9.

5. Polič, M.; Repovš, G. Cognitive map of Slovenia: Spatial representations and identity. Psychol. Sci. 2004, 46, 65-88.

6. Mizon, B. Light Pollution: Responses and Remedies; Springer: London, UK, 2002.

7. Carmoma, M. Place value: Place quality and its impact on health, social, economic and environmental outcomes. J. Urban Des. 2019, 14, 1-48. [CrossRef]

8. Kyba, C.C.M.; Hölker, F. Do artificially illuminated skies affect biodiversity in nocturnal landscapes? Landsc. Ecol. 2013, 28, 1637-1640. [CrossRef]

9. Schroer, S.; Hölker, F. Impact of Lighting on Flora and Fauna. In Handbook of Advanced Lighting Technology; Karlicek, R., Sun, C.C., Zissis, G., Ma, R., Eds.; Springer: Cham, Switzerland, 2017.

10. Longcore, T.; Rich, C. Ecological light pollution. Ecol. Environ. 2004, 2, 191-198. [CrossRef]

11. Briggs, W.R. Physiology of Plant Responses to Artificial Lighting, Ecological Consequences of Artificial Night Lighting. In Ecological Consequences of Artificial Night Lighting; Rich, C., Longcore, T., Eds.; Island Press: Washington, DC, USA, 2006; pp. 389-411.

12. Gaston, K.J.; Gaston, S.; Bennie, J.; Hopkins, J. Benefits and costs of artificial nighttime lighting of the environment. Environ. Rev. 2015, 23, 14-23. [CrossRef]

13. Rebernik, N.; Szajczyk, M.; Bahillo, A.; Goličnik Marušić, B. Measuring Disability Inclusion Performance in Cities Using Disability Inclusion Evaluation Tool (DIETool). Sustainability 2020, 12, 1378. [CrossRef]

14. Rebernik, N.; Goličnik Marušić, B.; Bahillo, A.; Osaba, E. 4-dimensional Model and Combined Methodological Approach to Inclusive Urban Planning and Design for ALL. Sustain. Cities Soc. 2019, 44, 195-214. [CrossRef]

15. Papalambrou, A.; Doulos, L.T. Identifying, Examining, and Planning Areas Protected from Light Pollution. The Case Study of Planning the First National Dark Sky Park in Greece. Sustainability 2019, 11, 5963. [CrossRef]

16. Balocco, C.; Volante, G.A. Method for Sustainable Lighting, Preventive Conservation, Energy Design and Technology—Lighting a Historical Church Converted into a University Library. Sustainability 2019, 11, 3145. [CrossRef]

17. Doulos, L.T.; Sioutis, I.; Kontaxis, P.; Zissis, G.; Faidas, K. A decision support system for assessment of street lighting tenders based on energy performance indicators and environmental criteria: Overview, methodology and case study. Sustain. Cities Soc. 2019, 51, 101759. [CrossRef]

18. Haans, A.; de Kort, Y.A.W. Light distribution in dynamic street lighting: Two experimental studies on its effects on perceived safety, prospect, concealment, and escape. J. Environ. Psychol. 2012, 32, 342-352. [CrossRef]

19. Ngarambe, J.; Kim, G. Sustainable Lighting Policies: The Contribution of Advertisement and Decorative Lighting to Local Light Pollution in Seoul, South Korea. Sustainability 2018, 10, 1007. [CrossRef]

20. Van Rijswijk, L.; Haans, A. Illuminating for Safety: Investigating the Role of Lighting Appraisals on the Perception of Safety in the Urban Environment. Environ. Behav. 2018, 50, 889-912. [CrossRef] [PubMed]

21. Hänel, A.; Doulos, L.T.; Schroer, S.; Gălătanu, C.D.; Topalis, F. Sustainable Outdoor Lighting for Reducing Energy and Light Waste. In Proceedings of the Improving Energy Efficiency in Commercial Buildings \& Smart Communities Conference, Frankfurt, Germany, 16-18 March 2016.

22. Boyce, P.R. The benefits of light at night. Build. Environ. 2019, 51, 356-367. [CrossRef]

23. CIE 150:2003; Guide on the Limitation of the Effects of Obtrusive Light from Outdoor Lighting Installation; CIE: Vienna, Austria, 2003.

24. Illuminating Engineering Society of North America. Light Trespass: Research, Results and Recommendations, TM-11-2000; IESNA: New York, NY, USA, 2000.

25. International Dark Sky Association. Outdoor Lighting Code Handbook; IDA: Tucson, AZ, USA, 2002.

26. Fotios, S.; Gibbons, R. Road lighting research for drivers and pedestrians: The basis of luminance and illuminance recommendations. Lighting Res. Technol. 2018, 50, 154-186. [CrossRef]

27. Laze, K. Assessing public perceptions about road lighting in five neighborhoods of Tirana, Albania. Int. J. Sustain. Lighting 2019, 21, 38-46. [CrossRef]

28. Fornara, F.; Bonaiuto, M.; Bonnes, M. Cross-Validation of Abbreviated Perceived Residential Environment Quality (PREQ) and Neighbourhood Attachment (NA) Indicators. Environ. Behav. 2010, 42, 171-196. [CrossRef]

29. Boyce, P.R.; Fotios, S.; Richards, M. Road lighting and energy saving. Lighting Res. Technol. 2009, 41, 245-260. [CrossRef]

30. Garvin, D.A. What Does “Product Quality" Realy Mean? Sloan Manag. Rev. 1984, 26, $25-43$.

31. Juran, J.M. How to Think About Quality. In Juran's Quality Handbook, 5th ed.; Juran, J.M., Godfrey, A.B., Eds.; McGraw-Hill: Washington, DC, USA, 1998; pp. 26-43.

32. Edwards, C.D. The Meaning of Quality. Qual. Prog. 1968, 1, 36-39.

33. Abbasi, A.; Alalouch, C.; Bramley, G. Open Space Quality İn Deprived Urban Areas: User Perspective and Use Pattern. Procedia Soc. Behav. Sci. 2016, 216, 194-205. [CrossRef] 
34. Boyce, P.R.; Eklund, N.H.; Hamilton, B.J.; Bruno, L.D. Perceptions of safety at night in different lighting conditions. Lighting Res. Technol. 2000, 32, 79-91. [CrossRef]

35. Gligor, A.; Grif, H.; Oltean, S. Considerations on an Intelligent Buildings Management System for an Optimized Energy Consumption. In Proceedings of the 2006 IEEE International Conference on Automation, Quality and Testing, Robotics, ClujNapoca, Romania, 25-28 May 2006; pp. 280-284. [CrossRef]

36. Cellai, G.; Secchi, S.; De Piccioli, S.M. Lighting Design for Psychophysical Wellbeing: Tools and Investigation Methods. In Proceedings of the Building Simulation Conference, Rome, Italy, 2-4 September 2019. [CrossRef]

37. Veitch, J.A. Lighting Guidelines from Lighting Quality Research. In Proceedings of the CIBSE Conference, York, UK, 9-11 July 2000.

38. Veitch, J.A. Psychological processes influencing Lighting Quality. J. Illum. Eng. Soc. 2001, 30, 124-140. [CrossRef]

39. Johansson, M.; Pedersen, E.; Maleetipwan-Mattson, P.; Kuhn, L.; Laike, T. Perceived outdoor lighting quality (POLQ): A lighting assessment tool. J. Environ. Psychol. 2014, 39. [CrossRef]

40. Boyce, P.R. Lighting research for interiors: The beginning of the end or the end of the beginning. Lighting Res. Technol. 2004, 36, 283-294. [CrossRef]

41. Säynäjoki, E.S.; Inkeri, V.; Heinonen, J.; Junnila, S. How central business district developments facilitate environmental sustainability-A multiple case study in Finland. Cities 2014, 41, 101-113. [CrossRef]

42. Sheikhnejad, Y.; Yigitcanlar, T. Scientific Landscape of Sustainable Urban and Rural Areas Research: A Systematic Scientometric Analysis. Sustainability 2020, 12, 1293. [CrossRef]

43. Jenkins, W. Sustainability theory. Berksh. Encycl. Sustain. 2009, 1, 380-384.

44. Cato, S.M. Green Economics: An Introduction to Theory, Policy and Practice; Earthscan: London, UK, 2009.

45. Poksinska, B.; Dahlgaard, J.J.; Antoni, M. The state of ISO 9000 certification: A study of Swedish organizations. TQM Mag. 2002, 14, 297-306. [CrossRef]

46. Cafuta, M.R. Open Space Evaluation Methodology and Three Dimensions Evaluation Model as a Base for Sustainable Development Tracking. Sustainability 2015, 7, 13690-13712. [CrossRef]

47. Rozman Cafuta, M. Visual Perception and Evaluation of Artificial Night Light in Urban Open Areas. Informatologia 2014, 47, 257-263.

48. Lynch, K. Site Planning; The MIT Press: Cambridge, MA, USA, 1962.

49. Rozman Cafuta, M. Public Lighting in The Communicative Urban Context. Informatologia 2010, 43, 122-125.

50. Painter, K.A.; Farrington, D.P. The Financial benefits of improved street lighting based on crime reduction. Light. Res. Technol. 2001, 33, 3-10. [CrossRef]

51. Yuen, B. Safety and dwelling in Singapore. Cities 2004, 21, 19-28. [CrossRef]

52. Kaklauskas, A.; Zavadskas, E.K.; RadzevicieneI, A.; Ubarte, I.; Podvezko, A.; Podvezko, V.; Bucinkas, V. Quality of city life multiple criteria analysis. Cities 2018, 72, 82-93. [CrossRef]

53. Peña-García, A.; Hurtado, A.; Aguilar-Luzón, M.C. Impact of public lighting on pedestrians' perception of safety and well-being. Saf. Sci. 2015, 78, 142-148. [CrossRef]

54. Zhu, Y.; Ding, J.; Zhu, Q.; Cheng, Y.; Ma, Q.; Ji, X. The impact of green open space on community attachment-a case study of three communities in Beijing. Sustainability 2017, 9, 560. [CrossRef]

55. Kim, S.; An, K. Exploring psychological and aesthetic approaches of bio-retention facilities in the urban open space. Sustainability 2017, 9, 2067. [CrossRef]

56. Xu, X.; Xu, X.; Guan, P.; Ren, Y.; Wang, W.; Xu, N. The Cause and Evolution of Urban Street Vitality under the Time Dimension: Nine Cases of Streets in Nanjing City, China. Sustainability 2018, 10, 2797. [CrossRef]

57. Montgomery, J. Making a city: Urbanity, vitality and urban design. J. Urban Des. 1998, 3, 93-116. [CrossRef]

58. Gehl, J. Cities for People; Island Press: Washington, DC, USA, 2010.

59. Gehl, J. Life between Buildings: Using Public Space, 5th ed.; The Danisch Architectural Press: Copenhagen, Denmark, 2001.

60. Goličnik, B. Vedenjski Zemljevidi Ljubljanskih Trgov in Parkov: Novi Izzivi in Pogledi na Načrtovanje in Urejanje Prostora; Urbanistični Inštitut Republike Slovenije: Ljubljana, Slovenia, 2006. (In Slovenian)

61. Carmona, M.; Heath, T.; Oc, T.; Tiesdell, S. Public Places-Urban Spaces: The Dimension of Urban Design; Architectural Press: Oxford, UK, 2003.

62. Dabbagh, E. The Effects of Color and Light on the Beautification of Urban Space and the Subjective Perception of Citizens. Int. J. Eng. Sci. Invent. (IJESI) 2019, 8, 20-25.

63. Debreczeni, G. Svetloba in arhitektura. In Razsvetljava'95., Proceedings of the Fourth International Symposium, Maribor, Slovenia, 11 May 1995; Orgulan, A., Ed.; Slovensko Društvo za Razsvetljavo: Maribor, Slovenia, 1995; pp. 35-42. (In Slovenian)

64. Pellegrino, A. Lighting control System to improve energy performance and environmental Quality of buildings: Limits and potentials. In Razsvetljava 2006, Razsvetljava delovnih mest, Proceedings of the Fifteenth International Symposium, Bled, Slovenia, 12-13 October 2006; Orgulan, A., Ed.; Slovensko Društvo za Razsvetljavo: Maribor, Slovenia, 2006; pp. 37-46.

65. Santen, C. Light Zone City: Light Planning in the Urban Context; Birkhaeuser: Basel, Switzerland, 2006.

66. Narboni, R. Lighting the Landscape: Art, Design, Technologies; Birkhauser: Basel, Switzerland, 2004.

67. Dubois, M.C. Shading devices and daylight quality: An evaluation based on simple performance indicators. Lighting Res. Technol. 2003, 35, 61-74. [CrossRef] 
68. Rea, M.S. Lighting Handbook: Reference and Application, 9th ed.; Illuminating Engineering Society of North America (IESNA): New York, NY, USA, 2000.

69. Rozman Cafuta, M.; Sitar, M. Rethinking the city spatial identity through the eyes of the observer. Prostor 2017, $25,316-327$. [CrossRef] 